\title{
The emotional impact of the COVID-19 outbreak on cancer outpatients and their caregivers: results of a survey conducted in the midst of the Italian pandemic
}

\section{Maria Silvia Cona}

Luigi Sacco University Hospital: Ospedale Luigi Sacco-Polo Universitario

\section{Eliana Rulli}

Mario Negri Institute for Pharmacological Research Branch of Milan: Istituto di Ricerche

Farmacologiche Mario Negri

Davide Dalu ( $\nabla$ davide.dalu@asst-fbf-sacco.it )

Ospedale Luigi Sacco: Ospedale Luigi Sacco-Polo Universitario https://orcid.org/0000-0002-80172149

\section{Francesca Galli}

Mario Negri Institute for Pharmacological Research Branch of Milan: Istituto di Ricerche

Farmacologiche Mario Negri

\section{Selene Rota}

Luigi Sacco University Hospital: Ospedale Luigi Sacco-Polo Universitario

\section{Sabrina Ferrario}

Luigi Sacco University Hospital: Ospedale Luigi Sacco-Polo Universitario

\section{Nicoletta Tosca}

Luigi Sacco University Hospital: Ospedale Luigi Sacco-Polo Universitario

\section{Anna Gambaro}

Luigi Sacco University Hospital: Ospedale Luigi Sacco-Polo Universitario

\section{Virginio Filipazzi}

Luigi Sacco University Hospital: Ospedale Luigi Sacco-Polo Universitario

\section{Sheila Piva}

Fatebenefratelli and Oftalmico Hospital: Ospedale Fatebenefratelli e Oftalmico

Nicla La Verde

Luigi Sacco University Hospital: Ospedale Luigi Sacco-Polo Universitario

\section{Research Article}

Keywords: COVID-19, survey, cancer patients, caregivers, emotional distress 
Posted Date: May 3rd, 2021

DOl: https://doi.org/10.21203/rs.3.rs-389777/v1

License: (9) This work is licensed under a Creative Commons Attribution 4.0 International License. Read Full License

Version of Record: A version of this preprint was published at Supportive Care in Cancer on August 25th, 2021. See the published version at https://doi.org/10.1007/s00520-021-06489-y. 


\section{Abstract}

INTRODUCTION The study investigates the emotional discomfort of cancer patients (pts) and their caregivers (CGs), who need to access the Oncology day-hospital to receive treatment during the COVID-19 pandemic in Italy.

METHODS This is a single-institution, prospective, cross-sectional study. From May to June 2020 the points of view of both the "players" were compared through 2 different multiple-choice questionnaires, enquiring demographic characteristics, changes in emotional status, interpersonal relationships with health professionals (HCPs) and self-perception of treatment outcomes.

RESULTS 625 pts and 254 CGs were enrolled. Female were prevalent and pts were generally older than CGs. $40 \%$ pts and $25.6 \%$ CGs thought they were at a greater risk of contagion because lived together with a cancer pts or accessed the hospital. Both pts (86.3\%) and CGs (85.4\%) considered containment measures a valid support to avoid the spread of infection. People with a lower education level were less worried about being infected with SARS-COV-2. Waiting and performing visits/treatments without CGs had no impact on the emotional status of pts (64.4\%), but generated in CGs greater anxiety $(58.8 \%)$ and fear $(19.8 \%)$ of not properly managing pts at home. The majority of pts (54\%) and CGs (39.4\%) thought the pandemic doesn't influence treatment outcomes. The relationship with HCPs was not negatively impacted for majority of pts and CGs.

CONCLUSIONS Starting from these data, we can better understand the current psychological distress of pts and their families in order to develop potential strategies to support them in this strenuous period of crisis.

\section{1: Introduction}

In February 2020, the coronavirus disease 2019 (COVID-19) outbreak swept Italy. To prevent the spread of the Sars-CoV-2 infection, starting from March 9th the Italian Government progressively introduced mitigation measures that drastically limited social interactions [1].

The "lockdown" led to substantial changes in people's lifestyles with a consequent negative impact on their psychological well-being. The limitations in daily activities, the social isolation combined with the fear of contracting the infection and the uncertainties related to this new and unexpected condition, have generated insecurity, anxiety and emotional distress [2]. Furthermore, the COVID-19 pandemic led to a reorganization of the Healthcare System, in particular for those people who needed to continue "lifesaving" treatments, as in the case of cancer patients (pts).

An important goal for the Oncologist is to guarantee the continuum of care for cancer pts, even during a period of sanitary crisis, despite the potential risk of COVID-19 infection. Delaying treatment of metastatic cancer pts can lead to disease progression, performance status deterioration and worsening of symptoms. On the other hand, the omission or delay of adjuvant therapies can increase mortality. The 
main International Societies of Oncology have issued recommendations aimed to mitigate the negative effects of COVID-19 pandemic on diagnosis and treatment of cancer pts. [3-7]

First of all, they recommended making a correct patient selection, categorising them into high, medium, or low priority, in order to minimise hospital access for those pts who could continue the treatment/surveillance while staying at home through online medical counselling (telemedicine) or home drug delivery. For outpatients who needed to access the hospital, it was crucial to adopt all procedures aimed to reduce the risk of potential contagion, through a correct triage at the entrance of the dayhospital and clinic, the use of individual protection devices and a reorganization of spaces in order to maintain social distancing. The implementation of these procedures led to the unavoidable consequence that patients accessed the hospital without caregivers (CGs), who could not stay with them in the waiting room and during the visit. All the activities (visits and therapy administration) took place in a new and unusual way, which could destabilize the already fragile emotional balance of pts and their CGs.

Several surveys on pts' insights are ongoing but to date no study has been published regarding CGs' perceptions, and nobody has analysed their opinion on these topics to see if they are in agreement or not.

The aim of our study is to evaluate how the COVID-19 pandemic impacted on the emotional approach to treatment of cancer outpatients and their CGs, and to compare the points of view of both pts and CGs. Investigating these aspects is important in order to understand the difficulties that cancer pts and their families are facing during this health crisis, and to develop adequate strategies to deal with them.

\section{2: Materials And Methods}

This is a single-institution, prospective, cross-sectional study of the Department of Oncology at Luigi Sacco Hospital, one of the Italian hospitals which was mostly involved in the COVID-19 pandemic. The survey was conducted on outpatients who were receiving active cancer treatment and their CGs. Data collection was performed from 5th May to 5th June 2020. We devised two different multiple-choice questionnaires ( 15 questions for pts and 17 for CGs) enquiring about demographic characteristics, changes in emotional status, interpersonal relationships with health professionals (HCPs) and selfperception of treatment outcomes. The answers could be "Yes", "Enough", "No" and "I don't know".

\section{1: Statistical methods}

The answers were categorized into two groups: "Yes" and "Enough" versus "No". If the proportion of subjects answering "I don't know" was higher than $5 \%$ in pts' questionnaires and $10 \%$ in CGs' questionnaires, the impact of the demographic characteristics on the answer "I don't know" was investigated. Differences in the answers to questions in both pts and CGs questionnaires were investigated by chi-squared test. Details on the matching of questions in the two questionnaires are provided in Table 1. 
Table 1

Matching of patients' and caregivers' questionnaires

\section{Patient questionnaire}

Triage utility

Do you think that the triage

(questionnaire and temperature

measurement) performed at the

entrance and the safety standards

applied during the stay are useful to

reduce the risk of contagion of COVID$19 ?$

$\begin{array}{ll}\text { Expenditure of } & \begin{array}{l}\text { Do you believe that the application of } \\ \text { time for triage } \\ \text { such procedures involves an excessive } \\ \text { expenditure of time? }\end{array}\end{array}$

Risk in the
patient
accompanying

Do you think that your caregiver/cohabiting people are more exposed to COVID-19 infection in relation to your hospital access?

\section{Caregiver questionnaire}

Do you think that the triage (questionnaire and temperature measurement) performed at the entrance and the safety standards applied during the stay are useful to reduce the risk of contagion of COVID19 ?

Do you believe that the application of these procedures involves an excessive expenditure of time?

Do you think that accompanying the patient to the hospital entails a greater risk of contagion for you than the healthy population?

$\begin{array}{ll}\text { Risk in the } & \text { Do you think that your } \\ \text { patient } & \text { caregiver/cohabiting people are more } \\ \text { cohabiting } & \text { exposed to COVID-19 infection in } \\ & \text { relation to your hospital access? }\end{array}$

$\begin{array}{ll}\text { Changes in } & \text { Do you think that the application of } \\ \text { personal } & \text { safety procedures has changed the way } \\ \text { emotional } & \text { you deal emotionally with the path of } \\ \text { status } & \text { care? }\end{array}$

Type of changes

If you answered yes to the previous question, how?

$\begin{array}{ll}\text { Changes in } & \text { Do you think that the application of } \\ \text { patient } & \text { safety procedures has changed the way } \\ \text { emotional } & \text { you deal emotionally with the path of } \\ \text { status } & \text { care? }\end{array}$

\section{Negative impact of pandemic on patient treatment}

\begin{tabular}{|c|c|}
\hline $\begin{array}{l}\text { Attention of } \\
\text { doctors on } \\
\text { COVID-19 }\end{array}$ & $\begin{array}{l}\text { Do you think that currently the attention } \\
\text { of doctors is more focused on COVID- } \\
19 \text { than on cancer treatment? }\end{array}$ \\
\hline
\end{tabular}

Balance of restrictions and the reduction of the risk of contagion
Do you think that cohabiting with the patient entails a greater risk of contagion for you than the healthy population?

Do you feel that not sharing the wait and not attending the visit has a negative impact on your emotional state?

If you answered yes to the previous question, how?

Do you feel that not sharing the wait and not attending the visit has a negative impact on the emotional state of the patient?

Do you believe that the pandemic can have a negative effect on the patient's treatment path?
Do you think that currently the attention of doctors is more focused on COVID19 than on cancer treatment?

Overall, do you believe that the negative aspects of the restrictions imposed are balanced by the reduction of the risk of contagion? 
We also evaluated the impact of demographic characteristics on the answers to each question, which was investigated by univariable and multivariable logistic regression models. Results were expressed in terms of odds ratios (ORs) and their $95 \%$ confidence intervals $(95 \% \mathrm{Cl})$.

A p-value $<0.05$ was considered statistically significant. Analyses were carried out using SAS statistical software (version 9.4).

\section{3: Results}

625 consecutive pts and 254 CGs were enrolled. The whole population was mainly made up of females: 407 (65.1\%) pts and 143 (56.3\%) CGs were female. Pts were generally older than CGs: 436 (69.8\%) were $>60$ years while the majority of CGs were $41-60$ years old $(128,50.4 \%)(p<0.001)$. Moreover, 315 (50.5\%) pts had a low education level (primary and secondary school) while 170 (67.5\%) CGs had a higher degree (high school or greater) $(p<0.001)$. All the demographic characteristics of pts and CGs are reported in Table 2.

About half of the pts $(330,52.8 \%)$ reached the hospital with their own CGs, who were usually a son/daughter $(104,40.9 \%)$ or the partner $(97,38.2 \%)$, and frequently lived together $(148,58.3 \%)$. The answers of patients' and CGs' questionnaires are reported in table 3 and 4 , respectively. 


\begin{tabular}{|c|c|c|c|}
\hline & $\begin{array}{l}\text { Patients } \\
\mathrm{N}=625\end{array}$ & $\begin{array}{l}\text { Caregivers } \\
\mathrm{N}=254\end{array}$ & P-value \\
\hline Age & & & $<0.001 *$ \\
\hline $18-40$ years & $26(4.2)$ & $13(5.1)$ & \\
\hline $41-60$ years & $163(26.1)$ & $128(50.4)$ & \\
\hline$>60$ years & $436(69.8)$ & $113(44.5)$ & \\
\hline Sex & & & $0.014^{*}$ \\
\hline Female & $407(65.1)$ & $143(56.3)$ & \\
\hline Male & $218(34.9)$ & $111(43.7)$ & \\
\hline Educational qualification & & & $<0.001 *$ \\
\hline Primary school & $100(16.0)$ & $13(5.2)$ & \\
\hline Lower secondary school & $215(34.5)$ & $69(27.4)$ & \\
\hline Upper secondary school & $230(36.9)$ & $125(49.6)$ & \\
\hline Higher education & $79(12.7)$ & $45(17.9)$ & \\
\hline Missing & 1 & 2 & \\
\hline \multicolumn{4}{|c|}{ Reason for patient being in hospital } \\
\hline Therapy & $174(27.8)$ & $67(26.4)$ & \\
\hline Visit & $451(72.2)$ & $187(73.6)$ & \\
\hline \multicolumn{4}{|c|}{ Accompanied by a relative/friend/caregiver } \\
\hline No & $295(47.2)$ & & \\
\hline Yes & $330(52.8)$ & & \\
\hline \multicolumn{4}{|c|}{ Relationship with the patient } \\
\hline Spouse & & $97(38.2)$ & \\
\hline Son/daughter & & $104(40.9)$ & \\
\hline Parent & & $11(4.3)$ & \\
\hline Other & & $42(16.5)$ & \\
\hline \multicolumn{4}{|c|}{ Do you cohabit with the patient? } \\
\hline No & & $106(41.7)$ & \\
\hline Yes & & $148(58.3)$ & \\
\hline
\end{tabular}


$\longleftarrow$

Page 8/24 
Patients

$\mathrm{N}=625$

Do you think you are at greater risk of contagion than the healthy population?

No

Enough

Yes

I don't know

Missing

Do you think that the triage (questionnaire and temperature measurement) performed at the entrance and the safety standards applied in the waiting room are useful to reduce the risk of contagion of COVID-19?

No

Enough

Yes

I don't know

Missing

Do you believe that the application of such procedures involves an excessive expenditure of time?

No

Enough

Yes

I don't know
$47(7.5)$

$54(8.7)$

$484(77.6)$

$39(6.3)$

1

$489(78.2)$

$32(5.1)$

$48(7.7)$

$56(9.0)$

Do you think that your caregiver/cohabiting people are more exposed to COVID-19 infection in relation to your hospital access?

No $349(55.9)$

Enough $64(10.3)$

Yes

I don't know $158(25.3)$

Missing 1

Do you believe that the application of safety procedures has changed the relationship with health care professionals?

No 


\begin{tabular}{|c|c|}
\hline & $\begin{array}{l}\text { Patients } \\
\mathrm{N}=625\end{array}$ \\
\hline Enough & $46(7.4)$ \\
\hline Yes & $71(11.4)$ \\
\hline I don't know & $51(8.2)$ \\
\hline \multicolumn{2}{|c|}{$\begin{array}{l}\text { Do you think that the application of safety procedures has changed the way you deal emotionally } \\
\text { with the path of care? }\end{array}$} \\
\hline No & $401(64.4)$ \\
\hline Enough & $20(3.2)$ \\
\hline Yes & $175(28.1)$ \\
\hline I don't know & $27(4.3)$ \\
\hline Missing & 2 \\
\hline \multicolumn{2}{|l|}{ If you answered yes to the previous question, how? } \\
\hline Increased anxiety & $86(53.4)$ \\
\hline Fear of the disease & $41(25.5)$ \\
\hline Sense of solitude & $15(9.3)$ \\
\hline Fear of not remembering what the doctor said during the visit & $17(10.6)$ \\
\hline Other & $2(1.2)$ \\
\hline Missing & 14 \\
\hline \multicolumn{2}{|c|}{ Do you think the pandemic could have a negative effect on your treatment? } \\
\hline No & $336(53.9)$ \\
\hline Enough & $60(9.6)$ \\
\hline Yes & $63(10.1)$ \\
\hline I don't know & $164(26.3)$ \\
\hline Missing & 2 \\
\hline \multicolumn{2}{|c|}{$\begin{array}{l}\text { Do you think that currently the attention of doctors is more focused on COVID-19 than on cancer } \\
\text { treatment? }\end{array}$} \\
\hline No & $357(57.1)$ \\
\hline Enough & $45(7.2)$ \\
\hline Yes & $74(11.8)$ \\
\hline
\end{tabular}




\begin{tabular}{|l|c|}
\hline & \multicolumn{1}{|c|}{$\begin{array}{c}\text { Patients } \\
\mathrm{N}=625\end{array}$} \\
\hline I don't know & $149(23.8)$ \\
\hline $\begin{array}{l}\text { Overall, do you believe that the negative aspects of the restrictions imposed are balanced by the } \\
\text { reduction of the risk of contagion? }\end{array}$ \\
\hline No & $91(14.6)$ \\
\hline Enough & $60(9.6)$ \\
\hline Yes & $298(47.7)$ \\
\hline I don't know & $176(28.2)$ \\
\hline Table 3. Patients' questionnaire. & \\
\hline
\end{tabular}


Caregivers

$\mathrm{N}=254$

Do you think that accompanying the patient to the hospital entails a greater risk of contagion for you than the healthy population?

No

Enough

Yes

I don't know

$42(16.5)$

Do you think that cohabiting with the patient entails a greater risk of contagion for you than the healthy population?

No

$186(73.2)$

Enough

12 (4.7)

Yes

$20(7.9)$

I don't know

$36(14.2)$

Do you think that the triage (questionnaire and temperature measurement) performed at the entrance and the safety standards applied during the stay are useful to reduce the risk of contagion of COVID19 ?

No

27 (10.6)

Enough

$18(7.1)$

Yes

$199(78.3)$

I don't know

$10(3.9)$

Do you believe that the application of these procedures involves an excessive expenditure of time?

No

Enough

Yes

I don't know
225 (88.6)

$9(3.5)$

$12(4.7)$

$8(3.1)$

Do you feel that not sharing the wait and not attending the visit has a negative impact on the emotional state of the patient?

No

Enough

Yes

I don't know
78 (30.7)

39 (15.4)

116 (45.7)

21 (8.3) 
Caregivers

$\mathrm{N}=254$

Do you feel that not sharing the wait and not attending the visit has a negative impact on your emotional state?

No

Enough

$30(12.0)$

Yes

$128(51.0)$

I don't know

$12(4.8)$

Missing

3

If you answered yes to the previous question, how?

Increased anxiety

$76(76.0)$

Fear of the disease

Sense of solitude

Other

$2(2.0)$

Missing

28

In this complex situation, do you think you can still interface with doctors properly?

No

9 (3.6)

Enough

$30(12.0)$

Yes

I don't know

$75(29.9)$

Missing

3

Do you believe that the pandemic can have a negative effect on the patient's treatment path?

No

$100(39.4)$

Enough

$22(8.7)$

Yes

$39(15.4)$

I don't know

$93(36.6)$

Do you think that currently the attention of doctors is more focused on COVID-19 than on cancer treatment?

No

$109(43.1)$

Enough

$19(7.5)$ 


\begin{tabular}{|l|l|}
\hline & $\begin{array}{c}\text { Caregivers } \\
\mathbf{N}=\mathbf{2 5 4}\end{array}$ \\
\hline Yes & $26(10.3)$ \\
\hline I don't know & $99(39.1)$ \\
\hline Missing & 1 \\
\hline $\begin{array}{l}\text { Overall, do you believe that the negative aspects of the restrictions imposed are balanced by the } \\
\text { reduction of the risk of contagion? }\end{array}$ \\
\hline No & $22(8.7)$ \\
\hline Enough & $21(8.3)$ \\
\hline Yes & $109(43.1)$ \\
\hline I don't know & $101(39.9)$ \\
\hline Missing & 1 \\
\hline Table 4. Caregivers' questionnaire. & \\
\hline
\end{tabular}

\section{1: Comparison between pts and CGs}

Table 5 reports the comparison between pts and CGs answers (see Table 1 for details on matching questions). 
Table 5

Comparison between patients' and caregivers' answers to questionnaire.

\begin{tabular}{|c|c|c|c|c|c|c|}
\hline & \multicolumn{3}{|c|}{$\begin{array}{l}\text { Answers categorized as } \\
\text { No, Enough, Yes, I don't know }\end{array}$} & \multicolumn{3}{|c|}{$\begin{array}{l}\text { Answers categorized as } \\
\text { No, Enough/Yes }\end{array}$} \\
\hline & Patients & Caregivers & P- & Patients & Caregivers & P- \\
\hline & $N=625$ & $N=254$ & & $N=625$ & $N=254$ & \\
\hline Triage utility & & & 0.227 & & & 0.163 \\
\hline No & $47(7.5)$ & $27(10.6)$ & & $47(8.0)$ & $27(11.1)$ & \\
\hline Enough & $54(8.7)$ & $18(7.1)$ & & 538 & 217 (88.9) & \\
\hline Yes & $\begin{array}{l}484 \\
(77.6)\end{array}$ & 199 (78.3) & & & & \\
\hline I don't know & $39(6.3)$ & $10(3.9)$ & & & & \\
\hline Missing & 1 & 0 & & & & \\
\hline Expenditure of time for triage & & & $0.003^{*}$ & & & $0.028 *$ \\
\hline No & $\begin{array}{l}489 \\
(78.2)\end{array}$ & $225(88.6)$ & & $\begin{array}{l}489 \\
(85.9)\end{array}$ & 225 (91.5) & \\
\hline Enough & $32(5.1)$ & $9(3.5)$ & & 80 & $21(8.5)$ & \\
\hline Yes & $48(7.7)$ & $12(4.7)$ & & & & \\
\hline I don't know & $56(9.0)$ & $8(3.1)$ & & & & \\
\hline $\begin{array}{l}\text { Risk in the patient } \\
\text { accompanying }\end{array}$ & & & $0.016 *$ & & & 0.130 \\
\hline No & $\begin{array}{l}349 \\
(55.9)\end{array}$ & $147(57.9)$ & & $\begin{array}{l}349 \\
(74.9)\end{array}$ & $147(69.3)$ & \\
\hline Enough & $\begin{array}{l}64 \\
(10.3)\end{array}$ & $35(13.8)$ & & $\begin{array}{l}117 \\
(25.1)\end{array}$ & $65(30.7)$ & \\
\hline Yes & $53(8.5)$ & $30(11.8)$ & & & & \\
\hline I don't know & $\begin{array}{l}158 \\
(25.3)\end{array}$ & $42(16.5)$ & & & & \\
\hline Missing & 1 & 0 & & & & \\
\hline Risk in the patient cohabiting & & & $<.001 *$ & & & $0.002^{*}$ \\
\hline No & $\begin{array}{l}349 \\
(55.9)\end{array}$ & $186(73.2)$ & & $\begin{array}{l}349 \\
(74.9)\end{array}$ & $186(85.3)$ & \\
\hline
\end{tabular}




\begin{tabular}{|c|c|c|c|c|c|c|}
\hline \multirow[b]{2}{*}{ Enough } & \multicolumn{3}{|c|}{$\begin{array}{l}\text { Answers categorized as } \\
\text { No, Enough, Yes, I don't know }\end{array}$} & \multicolumn{3}{|c|}{$\begin{array}{l}\text { Answers categorized as } \\
\text { No, Enough/Yes }\end{array}$} \\
\hline & $\begin{array}{l}64 \\
(10.3)\end{array}$ & $12(4.7)$ & & $\begin{array}{l}117 \\
(25.1)\end{array}$ & $32(14.7)$ & \\
\hline Yes & $53(8.5)$ & $20(7.9)$ & & & & \\
\hline I don't know & $\begin{array}{l}158 \\
(25.3)\end{array}$ & $36(14.2)$ & & & & \\
\hline Missing & 1 & 0 & & & & \\
\hline $\begin{array}{l}\text { Changes in personal } \\
\text { emotional status }\end{array}$ & & & $<.001 *$ & & & <. $001 *$ \\
\hline No & $\begin{array}{l}401 \\
(64.4)\end{array}$ & $81(32.3)$ & & $\begin{array}{l}401 \\
(67.3)\end{array}$ & $81(33.9)$ & \\
\hline Enough & $20(3.2)$ & $30(12.0)$ & & 195 & $158(66.1)$ & \\
\hline Yes & $\begin{array}{l}175 \\
(28.1)\end{array}$ & $128(51.0)$ & & & & \\
\hline I don't know & $27(4.3)$ & $12(4.8)$ & & & & \\
\hline Missing & 2 & 3 & & & & \\
\hline Type of changes & & & - & & & \\
\hline Increased anxiety & $\begin{array}{l}90 \\
(52.3)\end{array}$ & $77(58.8)$ & & & & \\
\hline Fear of the disease & $\begin{array}{l}43 \\
(25.0)\end{array}$ & $13(9.9)$ & & & & \\
\hline Sense of solitude & $\begin{array}{l}18 \\
(10.5)\end{array}$ & $12(9.2)$ & & & & \\
\hline $\begin{array}{l}\text { Difficulty in managing the } \\
\text { behaviour of the patient at } \\
\text { home due to no shared } \\
\text { communication with the } \\
\text { doctor or the nurse }\end{array}$ & $0(0.0)$ & $26(19.8)$ & & & & \\
\hline $\begin{array}{l}\text { Fear of not remembering what } \\
\text { the doctor said during the visit }\end{array}$ & $\begin{array}{l}18 \\
(10.5)\end{array}$ & $0(0.0)$ & & & & \\
\hline Other & $3(1.7)$ & $3(2.3)$ & & & & \\
\hline Missing & 453 & 123 & & & & \\
\hline $\begin{array}{l}\text { Changes in patient emotional } \\
\text { status }\end{array}$ & & & $<.001 *$ & & & <. $001 *$ \\
\hline No & $\begin{array}{l}401 \\
(64.4)\end{array}$ & 78 (30.7) & & $\begin{array}{l}401 \\
(67.3)\end{array}$ & 78 (33.5) & \\
\hline
\end{tabular}




\begin{tabular}{|c|c|c|c|c|c|c|}
\hline \multirow[b]{2}{*}{ Enough } & \multicolumn{3}{|c|}{$\begin{array}{l}\text { Answers categorized as } \\
\text { No, Enough, Yes, I don't know }\end{array}$} & \multicolumn{3}{|c|}{$\begin{array}{l}\text { Answers categorized as } \\
\text { No, Enough/Yes }\end{array}$} \\
\hline & $20(3.2)$ & $39(15.4)$ & & \multirow{2}{*}{$\begin{array}{l}195 \\
(32.7)\end{array}$} & \multirow[t]{2}{*}{155 (66.5) } & \\
\hline Yes & $\begin{array}{l}175 \\
(28.1)\end{array}$ & $116(45.7)$ & & & & \\
\hline I don't know & $27(4.3)$ & $21(8.3)$ & & & & \\
\hline Missing & 2 & 0 & & & & \\
\hline $\begin{array}{l}\text { Negative impact of pandemic } \\
\text { on patient treatment }\end{array}$ & & & ¿.001* & & & 0.008 * \\
\hline No & $\begin{array}{l}336 \\
(53.9)\end{array}$ & $100(39.4)$ & & $\begin{array}{l}336 \\
(73.2)\end{array}$ & $100(62.1)$ & \\
\hline Enough & $60(9.6)$ & $22(8.7)$ & & 123 & $61(37.9)$ & \\
\hline Yes & $\begin{array}{l}63 \\
(10.1)\end{array}$ & $39(15.4)$ & & & & \\
\hline I don't know & $\begin{array}{l}164 \\
(26.3)\end{array}$ & 93 (36.6) & & & & \\
\hline Missing & 2 & 0 & & & & \\
\hline $\begin{array}{l}\text { Attention of doctors on } \\
\text { COVID-19 }\end{array}$ & & & $<.001 *$ & & & 0.300 \\
\hline No & $\begin{array}{l}357 \\
(57.1)\end{array}$ & $109(43.1)$ & & $\begin{array}{l}357 \\
(75.0)\end{array}$ & $109(70.8)$ & \\
\hline Enough & 45 (7.2) & $19(7.5)$ & & 119 & $45(29.2)$ & \\
\hline Yes & $\begin{array}{l}74 \\
(11.8)\end{array}$ & $26(10.3)$ & & & & \\
\hline I don't know & $\begin{array}{l}149 \\
(23.8)\end{array}$ & 99 (39.1) & & & & \\
\hline Missing & 0 & 1 & & & & \\
\hline $\begin{array}{l}\text { Balance of restrictions and } \\
\text { the reduction of the risk of } \\
\text { contagion }\end{array}$ & & & $0.003^{*}$ & & & 0.114 \\
\hline No & $\begin{array}{l}91 \\
(14.6)\end{array}$ & $22(8.7)$ & & $\begin{array}{l}91 \\
(20.3)\end{array}$ & $22(14.5)$ & \\
\hline Enough & $60(9.6)$ & $21(8.3)$ & & $\begin{array}{l}358 \\
(707)\end{array}$ & $130(85.5)$ & \\
\hline Yes & $\begin{array}{l}298 \\
(47.7)\end{array}$ & $109(43.1)$ & & & & \\
\hline
\end{tabular}




\begin{tabular}{|c|c|c|c|}
\hline \multirow[b]{2}{*}{ I don't know } & \multicolumn{2}{|c|}{$\begin{array}{l}\text { Answers categorized as } \\
\text { No, Enough, Yes, I don't know }\end{array}$} & \multirow[t]{2}{*}{$\begin{array}{l}\text { Answers categorized as } \\
\text { No, Enough/Yes }\end{array}$} \\
\hline & $\begin{array}{l}176 \\
(28.2)\end{array}$ & 101 (39.9) & \\
\hline Missing & 0 & 1 & \\
\hline
\end{tabular}

About half of the cancer pts felt more vulnerable to COVID-19 compared to the general population (question P1: 250, 52.5\%). Pts were more worried than caregivers about the risk of exposing cohabiting people to the COVID-19 infection because of their frequent access to the hospital (question P4 and question C2: yes/enough 117 [25.1\%] vs. 32 [14.7\%], $p=0.002$ ).

Both pts and CGs considered the containment measures (triage at the entrance, social distancing, personal protective equipment) a valid support to avoid the spread of infection (question P2 and C3: 538 [92.0\%] vs 217 [88.9\%] respectively, $p=0.163$ ). Both pts and CGs believed that the containment measures did not involve an excessive expenditure of time, with a major prevalence of positive judgments in CGs compared to pts (questions P3 and C4: 489 [85.9\%] vs. 225 [91.5\%] p = 0.028).

A personal emotional change caused by waiting and performing visits and treatments without CGs was reported more by CGs $(158,66.1 \%)$ than by pts $(195,32.7 \%)$ (questions P6 and C6, p < 0.001). Specifically, 77 (58.8\%) CGs reported greater anxiety and $26(19.8 \%)$ had a fear of not managing the patients properly at home (question $\mathrm{C7}$ ). Moreover, CGs thought that the pandemic caused a negative impact on the emotional state of the pts more than what the pts themselves stated (questions P6 and C5: 195 [32.7\%] vs 155 [66.5\%], $p<0.001)$.

The majority of pts $(336,73.2 \%)$ and CGs $(100,62.1 \%)$ thought that the pandemic did not influence treatment outcomes, with a higher prevalence of positive answers in pts (questions P8 and C9, $p=0.008$ ). The relationship with HCPs was not negatively affected for both pts (question P5: 457, 79.6\%) and CGs (question C8:167, 94.9\%), but about a quarter of pts and CGs thought that the attention of HCPs was more focused on COVID-19 than on cancer treatment (questions P9 and C10: 119 [25.0\%] vs. 45 [29.2\%], $p=0.300)$.

\section{2: Impact of pts' characteristics on answers}

The results of logistic regression analyses on pts' questionnaires are summarized in Tables $6 a, b, c$ (supplementary file).

No statistically significant associations were found between age and sex and the answers to questions, although males were more likely to answer "I don't know" to the questions concerning the time spent for the triage and application of safety standards (question P3: adjusted OR [aOR] 1.78, 95\% Cl 1.01-3.15, p $=0.047$, online table S1). Compared to pts with a lower education level, those with an upper secondary school degree were more likely to think that cohabiting people were more exposed to COVID-19 infection 
due to their frequent access to the hospital (question P4: aOR $2.18,95 \% \mathrm{Cl} 1.08-4.41, \mathrm{p}=0.030$ ) and to declare a possible negative effect of the pandemic on their treatment (question P8: aOR $2.35,95 \% \mathrm{Cl}$ 1.11-4.99, $p=0.025$ ). Moreover, these pts were more likely to think that the attention of doctors was more focused on COVID-19 than on cancer treatment (question P9: aOR 2.60,95\% Cl 1.28-5.28, p = 0.009). In regards to the possibility of receiving "I don't know" as an answer, pts with a primary school degree had more difficulty in answering several questions (online table S1).

Moreover, pts who accessed the hospital for a visit were less likely to think they had a higher risk of contagion compared to pts who accessed it for the therapy (question P1: aOR $0.45,95 \% \mathrm{Cl} 0.30-0.69, \mathrm{p}<$ 0.001 ) and they were more likely to answer "I don't know" to the same question (aOR $2.12,95 \% \mathrm{Cl} 1.32-$ $3.40, p=0.002)$; more frequently they thought that the application of safety procedures had changed the relationship with HCPs and that the attention of doctors was more focused on COVID-19 (question P5: aOR 1.86, 95\% $\mathrm{Cl} 1.12-3.09, p=0.016$; question P9: aOR 1.96, 95\% $\mathrm{Cl} 1.17-3.25, p=0.010$ respectively). Finally, they were more likely to answer "I don't know" to this last question (question P9: aOR $1.76,95 \% \mathrm{Cl}$ 1.12-2.77, $p=0.015)$.

\section{3: Impact of CGs' characteristics on answers}

The results of logistic regression analyses on CGs' questionnaires are summarized in Tables $7 a, b, c$ (supplementary file).

No statistically significant associations were found between the answers and the demographic characteristics, except for sex and education level. Compared to female CGs, males were less likely to believe in a negative effect of the pandemic on pts' treatment (question C9: aOR $0.48,95 \% \mathrm{Cl} 0.24-0.96$, $p=0.039)$.

Compared to CGs with a low education level, CGs with a higher education level were more likely to think they were at a greater risk of contagion because they were accompanying (question C1: CGs with upper secondary school degree: aOR 2.56, 95\% Cl 1.12-5.86, $\mathrm{p}=0.026$; CGs with higher school degree: aOR $3.11,95 \% \mathrm{Cl} 1.17-8.26, \mathrm{p}=0.023$ ) or cohabiting with the pts (question C2: CGs with upper secondary school degree: aOR 4.48, 95\% Cl 1.24-16.2, $\mathrm{p}=0.022$; CGs with higher school degree: aOR $4.54,95 \% \mathrm{Cl}$ $1.06-19.5, p=0.042)$.

As for pts, some CGs had difficulty in answering the questions and checked the "I don't know" option. More details are available in online table S2.

\section{4: Discussion}

This is the first Italian survey aimed to investigate the emotional approach to the care of cancer outpatients and their CGs, who needed to access the day-hospital and clinic of the Department of Oncology during the pandemic. With this study, we wanted to collect the points of view of both the "players" to compare them and evaluate differences and points of agreement, in order to identify the most suitable strategies to support pts and their families in this strenuous period of crisis. 
We enrolled a large number of pts in only one month and these data reflect the attention of our cancer centre to the continuum of care and the participants' involvement in this topic. Enrolled pts were mostly female, aged $>60$ years old and with a low education level, while CGs were usually younger, female and with a higher education level. About half of the pts reached the hospital with their own CGs, however the number of questionnaires filled in by CGs was lower (77\% of CGs who accompanied pts to the hospital), probably because a part of them delivered pts to the hospital without accessing the cancer centre to avoid the potential risk of contagion.

What emerges from our survey is that the majority of pts felt more vulnerable to the SARS-CoV-2 infection compared to healthy people; this perception is coherent with the news reported by mass-media, drawn from the scientific literature. The first data about COVID-19 in cancer pts were published by Liang and colleagues in March 2020: in their cohort of 1590 COVID-19 positive Chinese pts, 18 had a history of cancer. The authors found that cancer pts had a higher risk of contracting COVID-19 because of their systemic immunosuppression and had a poorer prognosis than those without cancer [8]. Zang et al retrospectively studied the clinical features of 28 COVID-19 positive cancer pts from three hospitals in Wuhan: they observed that 15 (53.6\%) pts developed severe events with a mortality rate of $28.6 \%$, confirming that cancer pts presented a poor outcome with a high occurrence of clinically severe events and a high mortality [9]. The TERAVOLT study also confirmed the high mortality rate (33\%) and low admission rate to intensive care units in pts with thoracic cancer [10].

Differently from pts, CGs did not feel more exposed to infection although they were involved in taking care of someone who was undergoing active cancer treatment. This occurred even if they lived together with pts and needed to access the hospital for the pts' treatment.

Beyond this difference, we found that the education level influenced the perception of the risk of contagion: a higher education level probably led the person to gather more information about the pandemic and to a greater awareness of the severity of the health crisis, causing greater apprehension for their own safety. On the other hand, both pts and CGs with a low education level were more likely to answer "I don't know" to the question investigating this setting. These data are consistent with a previous survey aimed to analyse the different levels of risk perception in various populations during a health crisis, and the relative factors that influenced them [11-12].

Regardless of the perceived risk of contagion, study participants appreciated the application of general risk prevention and mitigation measures, as reported in literature [13].

CGs were particularly worried about the psychological well-being of their relatives: they believed that the pts' concern about the pandemic and the feelings of loneliness during the visit/therapy might add up to the apprehension for the disease and the effort to deal with a complex therapeutic plan. Moreover, since the access of the CGs to the hospital was limited, pts were alone during the visit and could not share information with the GCs. This situation resulted in the concern of CGs of not managing the patients properly at home. The most interesting finding of this study was that pts thought that the COVID-19 pandemic would not negatively impact the course of their treatment, the outcome of the therapy and the 
relationship with HCPs, despite the physical and mental load of their disease. This is probably due to the trust that a patient with a chronic disease has in the people who take care of him [14].

In a subgroup of survey participants, the fear of a "distraction effect" emerged. In fact, in our study we found that pts with a higher education level or pts who accessed the oncology department only occasionally (for example for a visit every six months) were concerned because they thought that COVID19 captured all the HCP's attention, overshadowing cancer treatment and prevention [15-18].

All the information acquired through this survey allowed us to better understand the emotional changes which occurred in cancer pts and their CGs during the COVID-19 pandemic. Starting from these data, we can develop potential strategies to help them cope better with the current psychological distress. Some suggestions could be for example to enhance online medical counselling (telemedicine) in order to minimise pts' exposure to COVID-19; to reorganise internal spaces and adopt protective measures also for CGs to allow them to have access to the visit with the pts in order to gain the necessary information about the pts' care; to spend time with people who have a lower education level in order to better explain the consequences of the pandemic and the behaviours to adopt to avoid contagion; to reassure pts and CGs that the priority of Oncologists is cancer care, which is their mission [19-22].

This study also has limitations. First of all, some selection bias exists due to the voluntary nature of participation. Moreover, even if the number of enrolled subjects is significant for a monocentric study, we have to consider that a number of data has been lost because of the inability of some pts to answer questionnaires (due to performance status, physical or cultural limitations) or the refusal to join the survey both of pts and CGs. Finally, there is a percentage of particularly apprehensive pts who have postponed visits/therapies and CGs who prefer not to access in the Day Hospital for fear of contagion: in these cases, submit the questionnaire was not possible.

To take care of a cancer pts does not only mean to administer therapy but to take care of a whole person, without disregarding the family environment and psychological well-being. A patient-centred care remains the best approach for a successful outcome, even more so during this devastating global pandemic.

\section{Declarations}

\section{FOUNDING:}

This research did not receive any specific grant from funding agencies in the public, commercial, or notfor-profit sectors.

\section{CONFLICTING INTERESTS:}

All the authors have no conflicts of interest to declare that are relevant to the content of this article.

AVAILABILITY OF DATA AND MATERIAL: all data are available in the manuscript and in the supplementary files 
CODE AVAILABILITY: not applicable

\section{AUTHORS' CONTRIBUTIONS:}

Maria Silvia Cona: Conceptualization, Writing - Original Draft, Writing - Review \& Editing

Eliana Rulli: Data Curation, Formal analysis, Writing - Review \& Editing

Davide Dalu: Writing - Review \& Editing

Francesca Galli: Data Curation, Formal analysis, Writing - Review \& Editing

Selene Rota: Data Curation

Sabrina Ferrario: Data Curation

Nicoletta Tosca: Data Curation

Anna Gambaro: Data Curation

Virginio Filipazzi: Data Curation

Sheila Piva: Writing - Review \& Editing

Nicla La Verde: Conceptualization, Writing - Original Draft, Writing - Review \& Editing, Supervision

All authors contributed to manuscript revision, read and approved the submitted version.

ETHICS APPROVAL

Ethical approval was gained from the internal Ethical Committee of the Luigi Sacco Hospital in Milan (Prot. nr: 34675/2020). Participants gave informed consent before filling the questionnaires. The information sheet included details on data anonymity and procedures for stopping participation.

CONSENT TO PARTICIPATE: all participants signed informed consent before filling the questionnaires

CONSENT FOR PUBLICATION: not applicable

\section{References}

1. Government of Italy Decree of the president of the Council of Ministers 9 March 2020. March9, 2020.https://www.gazzettaufficiale.it/eli/id/2020/03/09/20A01558/sg

2. Luo M, Guo L, Yu M, Jiang W, Wang H. The psychological and mental impact of coronavirus disease 2019 (COVID-19) on medical staff and general public - A systematic review and meta-analysis.

Psychiatry Res. 2020 Sep; 291:113190 
3. NCCN (National Comprehensive Cancer Network). Coronavirus disease 2019 (COVID-19) resources for the cancer care community. Available from: https://www.nccn.org/covid-19/

4. ASCO (American Society of Clinical Oncology). ASCO coronavirus resources. Available from: https://www.asco.org/asco-coronavirus-information)

5. ESMO (European Society for Medical Oncology). ESMO COVID-19 and cancer. Available from: https://www.esmo.org/covid-19-and-cancer

6. AIOM (Associazione Italiana di Oncologia Medica). Assicurare il proseguimento delle terapie salvavita per tutti i pazienti oncologici e onco-ematologici. Available from: https://www.aiom.it/wpcontent/uploads/2020/04/20200407_appello_AIOM-AIRO-SIE.pdf

7. AIOM (Associazione Italiana di Oncologia Medica).Rischio infettivo da coronavirus covid 19: indicazioni per l'oncologia. Available from: https://www.aiom.it/wpcontent/uploads/2020/03/20200313_COVID19_indicazioni_AIOM-CIPOMO-COMU.pdf

8. Liang W, Guan W, Chen R, Wang W, Li J, Xu K, Li C, Ai Q, Lu W, Liang H, Li S, He J. Cancer patients in SARS-CoV-2 infection: a nationwide analysis in China. Lancet Oncol. 2020 Mar;21(3):335-337. doi: 10.1016/S1470-2045(20)30096-6)

9. Zhang L, Zhu F, Xie L, et al. Clinical characteristics of COVID-19-infected cancer patients: a retrospective case study in three hospitals within Wuhan, China. Ann Oncol. 2020

10. Garassino MC, Whisenant JG, Huang LC, et al. COVID-19 in patients with thoracic malignancies (TERAVOLT): first results of an international, registry-based, cohort study. Lancet Oncol. 2020;21(7):914-922. doi:10.1016/S1470-2045(20)30314-4

11. de Zwart O, Veldhuijzen IK, Elam G, Aro AR, Abraham T, Bishop GD, Voeten HA, Richardus JH, Brug J. Perceived threat, risk perception, and efficacy beliefs related to SARS and other (emerging) infectious diseases: results of an international survey. Int J Behav Med. 2009;16(1):30-40)

12. Ding Y, Du X, Li Q, Zhang M, Zhang Q, et al. Risk perception of coronavirus disease 2019 (COVID-19) and its related factors among college students in China during quarantine. PLoS One. 2020 Aug 13;15(8):e0237626

13. Erdem D, Karaman I. Awareness and perceptions related to COVID-19 among cancer patients: A survey in oncology department. Eur J Cancer Care (Engl). 2020 Sep 18:e13309

14. Palmer Kelly E, Meara A, Hyer M, Payne N, Pawlik TM. Characterizing Perceptions Around the PatientOncologist Relationship: a Qualitative Focus Group Analysis. J Cancer Educ. 2020 Jun;35(3):447453. doi: 10.1007/s13187-019-1481-6.

15. https://www.nytimes.com/2020/04/20/health/treatment-delays-coronavirus.html

16. https://www.rcseng.ac.uk/news-and-events/blog/cancer-patients-the-forgotten-victims-of-the-covid19-global-pandemic/

17. https://www.fightcancer.org/releases/survey-covid-19-affecting-patients\%E2\%80\%99-access-cancercare 
18. Cortiula F, Pettke A, Bartoletti M, Puglisi F, Helleday T. Managing COVID-19 in the oncology clinic and avoiding the distraction effect. Ann Oncol. 2020; 31(5): 553-555. doi:10.1016/j.annonc.2020.03.286

19. Sirintrapun SJ, Lopez AM. Telemedicine in Cancer Care. Am Soc Clin Oncol Educ Book. 2018 May 23;38:540-545

20. Al-Shamsi HO, Alhazzani W, Alhuraiji A, Coomes EA, Chemaly RF, Almuhanna M, Wolff RA, Ibrahim NK, Chua MLK, Hotte SJ, Meyers BM, Elfiki T, Curigliano G, Eng C, Grothey A, Xie C. A Practical Approach to the Management of Cancer Patients During the Novel Coronavirus Disease 2019 (COVID-19) Pandemic: An International Collaborative Group. Oncologist. 2020 Jun;25(6):e936-e945

21. Mann DM, Chen J, Chunara R, Testa PA, Nov O. COVID-19 transforms health care through telemedicine: Evidence from the field. J Am Med Inform Assoc. 2020 Jul 1;27(7):1132-1135

22. Ohannessian R, Duong TA, Odone A. Global Telemedicine Implementation and Integration Within Health Systems to Fight the COVID-19 Pandemic: A Call to Action. JMIR Public Health Surveill. 2020 Apr 2;6(2):e18810

\section{Supplementary Files}

This is a list of supplementary files associated with this preprint. Click to download.

- SupplementaryTables.docx

- supplementaryfile.doc 